\title{
Interpretations of the Hidden
}

\author{
K. Thirumaran
}

\author{
James Cook University Australia, Singapore Campus
}

\begin{abstract}
Within the realms of tourism, there are a select group of inquisitive people eager to experience the mystery and mystique inspired by sites located off the beaten path andthus not frequented by domestic and international visitors. These sites attract curiosity and often demand a degree of bravery in or order to enter their liminal domains. Given these places are either hidden or closed to public view, this paper plumbs the experiences of non-mainstream organised university tours anddelves into detail of one particular failed tourist attraction, the Tang Dynasty, to expound on the idea that non-public domains are significant spaces of experiential learning. Tang Dynasty was a tourist attraction in the 1990s in Singapore.Despite ceasing operation in 1999, this failed attraction continues to attract visitors into spaces that I have deemed the 'non-public domain.' In this context, I shall explore how a non-public domain site Inspires learning for defiant sojourners.
\end{abstract}

\section{The Entrance}

$\mathrm{T}$ his paper analyses a former Singapore tourist attraction called 'Tang Dynasty' in a retrospective period after its closing in September 1999. After this time, visitors clandestinely entered and absorbed its scenic beauty despite its decrepit state. Once occupying 12 hectares of land and costing around SGD\$100 million, Tang Dynasty was a theme park representing a $7^{\text {th }}$ century Chang'An village entertaining visitors with Chinese acrobatic performances, pony rides, an exhibition of the first emperor Shih Huang Ti's Terracotta Warriors, a themed amusement called the Ghost Mansion and a typical village house setting of the period. As part of the fieldwork learning experience for tourism and sociology students, the Tang Dynasty is one of several closed attractions that are visited. This attraction, which is not meant for public view, allows the students to reflect upon failed attractions, and how these places continue to attract ordinary and curious visitors who are undeterred by signs barring entry.

Employing discourse analysis and phenomenology, this paper explores the non-public domain as an interstitial space that is restricted, forbidden, related to danger and potentially mystical. It invites curious trespassers to wonder and wander in its realms. Though this paper offers a social and cultural analysis, it is not the intention of the author to suggest a way to appreciate hidden attractions, but rather to bring to attention an understanding of these forgotten domains and how they are interpreted by intrepid students and other visitors.

Having personally experienced the park in its heyday, as well as after its closing, I conclude that Tang Dynasty provides a unique case study for analysing the non-public domain. This liminal space bears witness to streams of visitors undeterred by boards blocking the entrance and hand written signs declaring 'No Entry'. The way to the entrance is worn with footpaths. Planks have been pushed aside so that anyone daring enough to enter this 'out-of-bounds' 
attraction can squeeze through. Having visited this site many times, I can see the evidence of how this repeatedly infringed entrance has been reinforced with stronger material or doubly layered wooden planks. Yet such reinforcements do not deter curious and interested visitors.

Tang Dynasty epitomizes the 'non-public domain.' Here non-public domain refers to a space which is neither public nor private and yet a domain owned by some entity. In the case of the Tang Dynasty, the space was transferred by the operator, Admiralty Leisure Pte Ltd., to the Jurong Town Corporation, a government agency overseeing industrial use of land. Though the agency has held the place for several years, it has remained dormant, becoming a space for visitors curious about the attraction's past. Its very existence, as can be gleaned fromPicture 1 in this paper, suggests a formidable resemblance to that of the Great Wall of China.

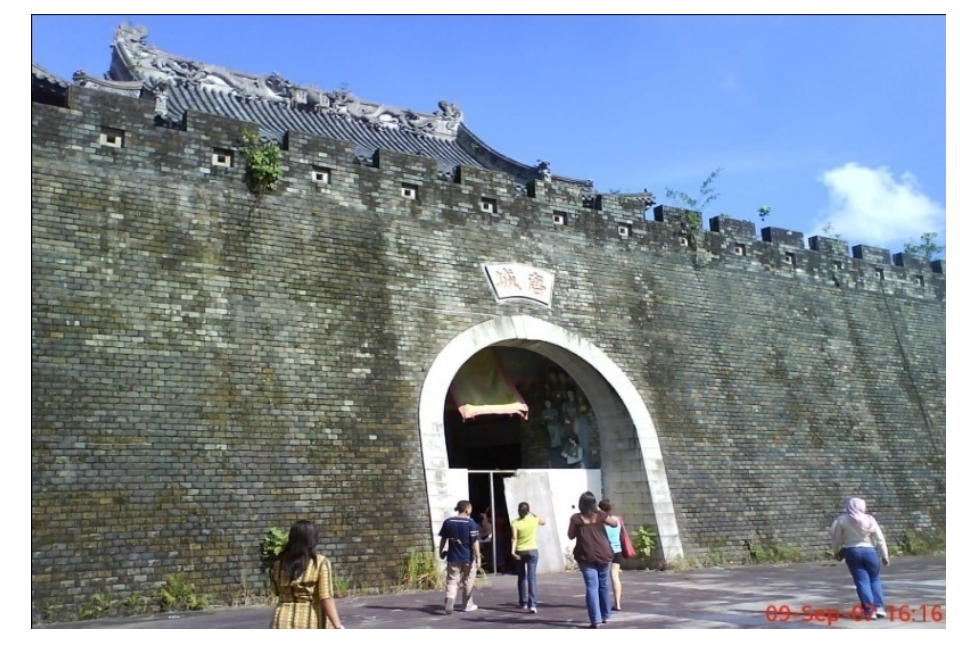

Picture 1.The Entrance of the Tang Dynasty with Loose Planks.

Hence, unfamiliar passers-by must wonder what it is, and many have gone on to venture into its premises. The Tang Dynasty therefore officially represents a defunct attraction, however it is a living attraction for those who dare to visit it.

Nation states decide on the attractions available for tourists, and those which are to be kept out of sight. Singapore is an economic success story with a clean, green cityscape and one of the top five travel destinations ( $\mathrm{Ng} 2012$ ). The city state has attractions similar to those found in many parts of the world, but with a certain localised uniqueness. Some of the older attractions run by government linked companies (GLC) receive excellent promotion and support by the tourism authorities. The Singapore Tourism Board (STB), being the public administrator for tourist attractions, has a major role in deciding upon public domain attractions. The non-public domain, to the contrary, is created by alternative publics and thrill seekers. STB's recognition and support can contribute to the visibility and promotion of attractions. Given the complex choices governments make, chances remain for some vernacular and extraordinary attractions to remain simultaneously out of sight of the mainstream, yet as sights of wonder and desire for the adventurous few. The risk of irrelevance for attractions not promoted as an official tourist site are very real. They may eventually be subject to redevelopment or left to fall into a state of disrepair. 
Site attractions exist because humans endow them with meaning for various reasons ranging from commercial, national, educational to cultural and special interest. The decision to select a place or site as an attraction entails complex considerations, negotiations and investments. Such decisions take into account both local realities and global influences. This discriminating process determines what is for the public - the public domain; what is not for the public - the non-public domain, and what is for the exclusivity of individuals - the private domain. Therefore, a non-public domain is a space/place that is a national property yet restricted from public use. It is both interstitial and liminal in that non-public space exists between the realms of 'public' and 'private'. The very existence of the 'non-public' domain opens up queries regarding its existence. Such spaces are publically 'owned' yet not open to the public. They are also not private spaces as they do not encompass the exclusive property of individuals.

The following are some of the titles of the over 60 student tours conducted from 2003 to 2011 that have incorporated visits to non-public domain sites: Sex and Spirits Tour, 24 Hours Tour, What's Hidden Tour? and the 12 Hours of Midnight Tour. These tours are not the ordinary type of higher education student excursion. From an organizer's perspective, much of the purpose of these tours has to do with showcasing sites and practices that are little known, unintentionally hidden or restricted from the public. Students journeying on these tours desire to access the forbidden, with many actively seeking 'ghostly encounters'. As the non-public domain is both interstitial and liminal in character, it is not surprising that they are frequently the sites of ghostly encounters.

\section{Reading In-Sights}

Much of the literature that comes close to addressing the notion of the non-public domain as presented above is scarce. Tegelberg (2010) investigates Lonely Planet's attempt to only highlight Cambodia's attractions that are meant to appeal to Western travellers. Local perspectives are largely left out. Tegelberg also suggests that Lonely Planet's approach to describing destinations is problematic. This suggests that the producers of travel guides adopt a particular approach which is not all encompassing.

Gutic, Caie and Clegg (2010) discover that visitors to the English Chichester Cathedralare seeking spiritual experiences and at the same time are motivated by the history of the place. Sewlyn (1996) comments that visitors to attraction sites experience both physical and emotional sensations. In some cases, visitors may be thinking of the past and present connections to the attractions while in other instances, the attraction could just simply be an inspiring experience devoid of time and place. The dichotomy between public and non-public spaces relays a tension between landscape as an asset and as a perception (see also Tress \& Tress, 2001).

Informal sites are often missed by visitors who are carefully channelled through to main streamattractions touted by tour operators, tour brochures, national authorities' websites and other collaterals. These public sites, come tourist destinations, are carefully crafted and officially narrated to encourage visitors to feel good about their experience (MaCannell 1976; Wang 1999 and Chhabra, Healy \& Sills, 2003).

National authorities do not wish to present the negative aspects of a destination, however visitors may wish otherwise; they frequently seek out a more 'authentic' experience of the 
host domain to understand what life is really like; its failures, hardship and all (Yvette, 2009; Seongseop \& Mckercher, 2011).

This is uneasy relationship is expressed through Dovey and King's work on slum tourism:

On the one hand informal urbanism can be picturesque with elements of nostalgia and a quest for authenticity; on the other is the shock of the real, the spectacle of intensive labyrinthine urbanity and an uneasy voyeurism (2012, p. 275).

A good number of tourists prefer to see and experience the 'real' destination rather than the 'made up' one prepared and staged for the public domain. It is this interstitial space and time that creates a non-public domain where experiences are not dictated by a tour guide or an attraction's attendant. The experience is narrowed to the senses of sights, sounds, sensations and interactions between the visitors.

\section{In The Tang Dynasty}

As a tour site for students, I firstly selected Tang Dynasty because it symbolises, at the national level, a failed tourism project for a country admired for so many economic successes and social structural stabilizers. Singapore's landscape is carefully engineered and authorities abhor allusions to failure. Secondly, in spite of Tang Dynasty's lacklustre capability as a tourist attraction, the closed spacecontinued to entice visitors who sought to breakthrough entry barriers to admire the attraction. Thirdly, very little has been written about thrillseeking Singaporeans, who do exist, despite government restrictions and a predominantly highly law abiding society. These reasons combine to provide a fascinating revelation of sites that are often interesting to a segment of a society but not promoted or kept up for larger national or international audiences. This paper integrates the idea of hidden interpretations and deviant tours to explain ways in which a place's significance is valued though officially downgraded or closed to public view.

People make meaning of their lived experiences and the very study of these experiences and observations is called phenomenology (Sharpley \&Stone 2012; Starks \& Trinidad 2007; Szarycz 2009; Wang 1999). This method is especially useful to understand the experiences of a small minority of people whose activities and experiences have been excluded by dominant voices and landscapes. Describing discourse analysis, Parker (1992) states that once a discussion and description of a phenomenon takes place, it is inevitable to relate to it as though it is real. The method also enables the construction of a narrative that articulates the nuances of a situation. A 'thick description' can narrate the way a particular community journeys through the hidden, marking a shift away from the dominant discourse. According to Sharkey "hermeneutic phenomenology always seeks to open up a middle space of rich engagement between the research object and the researcher"(2001, pp. 16-17). As part of the research, I too journeyed with the students absorbing their responses to scares, shadows and sounds in the disused Tang Dynasty site, in order to interpret how these experiences are culturally contextualised.

The discussion and extractions from my observations, participations and interviewinteractions with various participants are limited to those 'deviant' visitors and does not purport to make claims or generalise the issues as representative on a wider scale (see also Szarycz 2009). However, the outcome of this study does highlight the significance of 
interpretations of the hidden/non-public as a real experience. My research seeks to fill lacunae in tourism literature about ways in which non-public domain sites can become attractions in themselves, producing alternative narratives of local cultures and contexts.

\section{The 12 Hours of Midnight Tour}

Over the past 7 years, I have conducted tertiary level student tours that have taken students to places and sites unknown to tourists and seldom visited by locals. These tours, though educational in nature, are not typical learning journeys. As can be seen in the Table 1 below, some of these tours do actually have students walk through red light districts and cemeteries after midnight.

Students who have sought consent from their parents are reminded of appropriate attire and things to bring with them such as torchs, an extra change of clothes and insect repellent. During the tours I interpret the landscape providing the historical background and significance of the site to participants. However, in the last two years I have been fortunate to have two of my experienced students conduct the tours on my behalf. This has provided me with opportunities to observe the participants and mingle with the group as one of the participants myself. Most students challenge the unknown and some disbelieve the idea of the supernatural. Many more do not see the point of such attractions being blocked off from public viewing. A lot of questions arise but are hard to explain without a cultural and local context.

Given the numerous sites that we visit in the 12 hours from 8.30pm to 8.30am the next day, it would be too lengthy to analyse all the tours and aspects if each in this paper. Though each of the sites visited are different and the experiences unique, they share one common thread they are all mostly in the non-public domain. Therefore, from here on, the Tang Dynasty attraction will be analysed as a principal example.

Table 1.A Selected Number of Tour Sites not Promoted to Tourists or Locals

\begin{tabular}{|l|l|l|}
\hline Attractions & Significance & State Plans \\
\hline $\begin{array}{l}\text { Geylang Malay Village: } \\
\text { KudaKepang }\end{array}$ & $\begin{array}{l}\text { A traditional performance from } \\
\text { Java. Performed during some } \\
\text { Malay weddings and special } \\
\text { occasions. A little controversial } \\
\text { due to its animistic nature and } \\
\text { departure from Islamic teachings. }\end{array}$ & $\begin{array}{l}\text { Location of this performance is } \\
\text { now under a make-over and the } \\
\text { performance has been stopped at } \\
\text { the time of writing. }\end{array}$ \\
\hline $\begin{array}{l}\text { Red Light Districts of } \\
\text { Andang and JooChiat. } \\
\text { where transvestites are } \\
\text { picked up }\end{array}$ & $\begin{array}{l}\text { A misfit in a city that presents } \\
\text { itself as modern city state, clean } \\
\text { and void of vices. }\end{array}$ & $\begin{array}{l}\text { No state plans. } \\
\text { trict police enforcements of } \\
\text { legal workers in the trade. }\end{array}$ \\
\hline $\begin{array}{l}\text { The Alkaff Mansion } \\
\text { Formerly, a wealthy merchant's } \\
\text { house that has changed hands. } \\
\text { Today it's under the state’s } \\
\text { jurisdiction. Reported to be } \\
\text { haunted. }\end{array}$ & $\begin{array}{l}\text { The mansion currently is } \\
\text { occupied by a tenant running an } \\
\text { Italian restaurant: Alkaff } \\
\text { Mansion Ristorante }\end{array}$ \\
\hline
\end{tabular}




\begin{tabular}{|l|l|l|}
\hline Matilda's House & $\begin{array}{l}\text { Built around 1902, Set in } \\
\text { Punggol, it is the only house of its } \\
\text { time that remains undemolished. } \\
\text { Stories of ghostly sightings } \\
\text { abound. Formerly owned by an } \\
\text { Irish family during the colonial } \\
\text { era. }\end{array}$ & $\begin{array}{l}\text { The state plans to allow a } \\
\text { private condominium company } \\
\text { to take care of it as a conserved } \\
\text { building - turning it into a } \\
\text { condominium clubhouse }\end{array}$ \\
\hline The Changi Hospital & $\begin{array}{l}\text { Formerly a hospital and has been } \\
\text { closed since 1998. It has been an } \\
\text { attraction for many in the late } \\
\text { nights and early mornings as } \\
\text { people seek to experienceits } \\
\text { ghostliness. }\end{array}$ & $\begin{array}{l}\text { No development plans have } \\
\text { been implemented as of yet. }\end{array}$ \\
\hline Bukit Brown Cemetery & $\begin{array}{l}\text { A well-known site and burial } \\
\text { place of Singapore's pioneers. }\end{array}$ & $\begin{array}{l}\text { Part of the cemetery is now } \\
\text { for a highway extension. }\end{array}$ \\
\hline
\end{tabular}

When Tang Dynasty was first opened, the price of entry was about \$16 per adult. The price kept increasing over the years as the attraction neared its last days. The price alone was a deterrentto both domestic and international visitors. This commodification was part of the attractions failure. On the commodification of goods, Watson and Kopachevsky, interpreting Marx,note that:

In the process of commodification, human relations become objectified as relations between things, and money is hoisted as the universal "doubly abstract" medium of exchange, the primary measure of value, if not the symbol of general alienation, having the chief function, as Marx put it, to supply commodities with the material for the expression of their values--the commodity of commodities (1994, p. 650).

People visit an attraction based on interest and affordability. But in the case of non-promoted attractions or non-operating attractions where admission is free, then the issue of commodification is superseded by genuine interest. In the case of the Tang Dynasty, there is a natural demand given that people are able to trespass without punitive repercussions. In a society where the tourism landscape and cultural activities are highly controlled and managed domains, heritage or interest sights that may not appear to have a larger social or commercial function tend to be neglected. Given that an area could be cordoned off from the public to either protect the attraction from deterioration or to prevent people from getting in, it is significant that the consumption of these attractions is based on interest and desires. Visitors still risk a jump over the fence just to get a thrill out of visiting the attraction. More heartpalpitating experiences come from the hunt and look-out for ghosts.

\section{Multiple senses at work}

One unique attraction in the Tang Dynasty was the Ghost Mansion. During the time of the officially opened theme park, visitors to theGhost Mansion, were led inside in batches of eight and asked to sit around a dining table in a room that looked normal. They were given headphones to wear and when the lights were turned off, the room was completely dark and there were shadows moving, tables and chairs shaking and eerie voices played through the earphones. In the period after the attraction had closed down, tours of the Ghost Mansion 
happen without earphones,with the dining room area in complete darkness, and a 'skeleton' still standing in a corner. The place is still eerie. The heightening and play of senses is still at work despite the absence of artificial creations of sounds and effects.

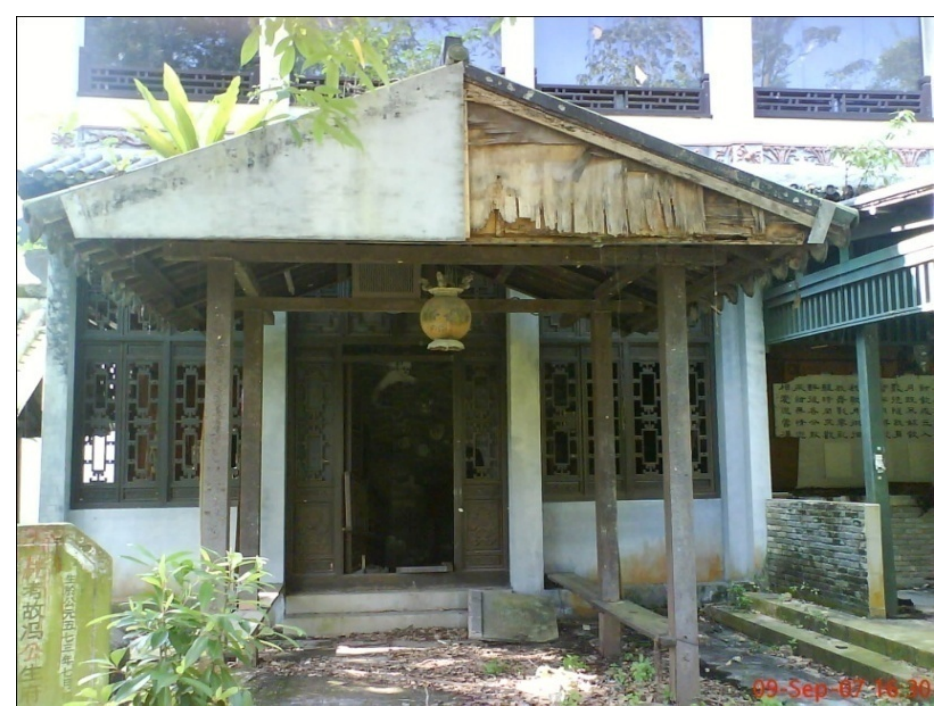

Picture 2. The Ghost Mansion doorway.

Often the slightest movement can startle the students who are already in a setting where the atmosphere is dark and silent. When doors creak, or shadows form even within darkness, some of the students hold each other tightly as they move through the Tang Dynasty's clusters of buildings. Sometimes mischievous or playful students in the group purposefully throw a stone ahead or make some funny noises, frightening the rest. Fun it may be, but the eyes of the weary students are alert, in the predawn dark, for the unexpected to turn up - a ghost.

Except for one very odd occasion, the many student groups that have been led through the Tang Dynasty have faced no consequential incidents. On that one occasion, at one of the Tang Village houses in the attraction's complex, the whole group heard a short shrill voice lasting for a brief two seconds. The shrill voice obviously did not originate from any of the students. In that moment, the whole group ran out of the building in a hysterical response. I must add that I too run out with the group. Though there could be scientific explanation for the shrill voice, for shadows or creaking doors, those experiences are indeed the type of sensations the students were expecting and sought to discover for themselves. Yet none dared to explore further the cause of the strange encounters except to expound on theories that related to culture or an expression of momentary hysteria.

In another incident, some of our cameras were able to photograph the presence of orbs. Orbs according to some studies (Orbs, 2007; Ehl, 2012 \& Raymond, 2006) are dust particles floating in the air that have a reflective effect and are depicted in a large air-like round shape, mostly chalky white, when a picture is taken. Some of our cameras are able to photograph orbs, or have orbs appear in the photographs, while other cameras have no such images present. Visitors to this intermediary realm frequently report sightings of orbs and apparitions. 
Another explanation to the presence of orbs is the presence of spirits. Some of us who could see apparitions with the naked eye will swear that they can see the orbs 'moving' and that that their size is roughly that of a human being. Many of the students I have discussed this experience with, have propounded different theories about it. One such theory, is that it is a spirit that is in a defensive position and as much as we are afraid of them, they too are afraid of us - especially as we form a large group. In this case, the orb is interpreted to be in a crouched position, sometimes forming a light white 'flurry' or 'airy' ball.

When a suspected spirit is sighted, the group is normally asked to move away or change direction. This is in partly as a mark of respect not to intrude into the spirits space. However, additionally, in the cultural context of Singaporean, Malay, Indian and Chinese belief systems, there is always a risk that a sensitive student will experience 'possession' or 'trance'. There is a sense of responsibility on my part to ensure that students are not harmed in any way possible even though, students have signed an indemnity form that they are responsible for their well-being throughout the tour. During our night visits the Tang Dynasty is pitch dark and even though many of us carry flashlights, it is still a large place with several blocks of village style houses and buildings and with thickets of trees and bushes here and there. It would be impossible to control the situation if someone in the group became possessed, and I do not have the knowledge or skills to prevent or expel spirits from a person. I do however, pray before these tours - seeking the blessings of God for the tour to be safe and successful.

Besides the fear factor, the sights also create a sense of awe and wonder. Some of the mural paintings on the wall depicting Tang culture and daily life are admired by many students. The murals also depict graffiti, and we have noted slogans such as: "Ghost is here", "I was here", "you nuts = eunuchs" and many more. Despite briefing my students not to write or do anything to the wall, there have been a couple of occasions when the temptation to write proved irresistible. When asked why they scribed graffiti on the wall, the common student response was "as a memory that I was here." A phenomenological analysis would question who or what is remembering or be reminded. Rather than assuming that this memory referred only to the student, an analysis would extend to notions of places as remembering or spirits of places. Such an analysis intersects with animist belief systems. Or perhaps the memory is for other visitors.

The student tours are often not the only groups present. Other Singaporean groups may also be touring. One such group is the Matts - a reference to Malay youngsters who gather on motorcycles and hangout. They may be identified by the bandanas that they wear on their heads. This sub-cultural group are friendly and when encountering them, there is usually a smile and greeting exchanged. Once in a while there is an exchange of experiences or an advisory not to go to a particular spot because someone saw something strange. There are also other people who use these non-public domains, these semi hidden places, to conduct small rituals to seek good fortune from the spirits. They normally burn a couple of candles and joss sticks to incant the spirits for lucky numbers in the 'Singapore 4D' or 'TOTO' national lottery. In respect of their ritual practice, we avoid passing too close to them and move on fast so as not to stir much attention.

\section{Afterwards}

These student tours are primarily conduits for knowledge dissemination. They serve a purpose in national education, beyond the usual industry experience (Kam, Xiang, Bing \& 
Petrick, 2010; Crispin \& Robinson, 2001). Knowledge is not limited to public domains. Nonpublic domains are equally fertile grounds that encourage students in deep analysis and reflective practice, asking them to recall associations and stories that relate to actual experiences. In this instance, sites such as the former Tang Dynasty offer possibilities for higher level learning and thinking. Traditional higher education in tourism, business and sociology, is concentrated in the domains of 'the known'. But experiences in the non-public domain showcase knowledge of the unseen and unknown. As a mainstream attraction Tang Dynasty failed, but as an unofficial and closed site it has enjoyed relative success. Clearly, dilapidated and deteriorating attractions facilitate the attribution of meaning in ways that formal and mainstream attractions cannot. Student tours of derelict sites play a valuable role in students' experience, understanding and analysis of tourism places - both official and unofficial. The tours are a valuable way of gaining knowledge by allowing students to have an educational experience that would not be available in the lecture theatre or tutorial room or by visiting public domains. The students tours enter liminal spaces and from this interstice new forms of knowledge and understanding arise.

Singapore's' tourism industry advertises shining buildings and attractions, artificial amusement parks and pockets of (exotic) 'culture' through Little India, China Town, Kampong Glam etc. However, failed tourism industry projects, such as the Tang Dynasty, as well as other non-public domains are attracting local non-mainstream visitors. One such example is the cultural heritage site of Bukit Brown Cemetery which houses graves of Singapore's early pioneers. Although exhumations are in process to make way for a highway extension (Brown, 2012) and the site is currently restricted to visitors - there is a substantial public call to preserve at least some of the cemetery's sites. And these sites are associated with spirits. Just as sites can move from public domains to non-public domains, so too can they move in other directions. An example of a site that has moved from a non-public domain back into the public and private domain is the popularly known haunted house called 'Matilda's House.' It is slated to be a club house within a private housing complex (Lim, 2012).

What these sites share in common is their location in the betwixt and between of the nonpubic domain. Here where forces of fear are superimposed upon a terrain of "No Entry". Individuals and groups find it adventurous to explore a site that is out of bounds to the public and discover the site's closed secrets, interpreting them in ways reflective of their time and society.

\section{WORKS CITED}

Brown study: A Singapore cemetery. (2012, Mar 17). The Economist, 402, 50. Retrieved from http://search.proquest.com/docview/940855324?accountid=16285

Chhabra, D.; Healy, R. \& Sills, E. (2003). Staged Authenticity and Heritage Tourism. Annals of Tourism Research, 30 (3), 702-719.

Crispin, D. \& Robinson, N. (2001). The theming of tourism education: a three-domain approach. International Journal of Contemporary Hospitality Management,13 (1), 3034. 
Dovey, K. \& King, R. (2012). Informal Urbanism and the Taste for Slums. Tourism Geographies: An International Journal of Tourism Space, Place and Environment, 14 (2), 275 - 293.

Ehl, D. (2007, Nov 13). Ghosts, spirits and orbs, oh my. McClatchy - Tribune Business News. Retrieved from http://search.proquest.com/docview/463645333?accountid=16285

Gutic, J., Caie, E.\& Clegg, A. (2010). In search of heterotopia? Motivations of visitors to an English cathedral. International Journal of Tourism Research, 12 (6), 750-760.

Kam, H. , Xiang, R. L., Bing, P. \&Petrick J. F. (2010). Knowledge Dissemination in Tourism Education: A Case of Tourism Marketing. Journal of Travel \& Tourism Marketing, 27 (5), 519-532.

Lim, Y. H. 18 (2012). 'Matilda House gets new life as condo clubhouse.' TheStraits Times, 18 October.

MacCannell, D. (1976). The Tourist. New York: Schocken Books.

Ng, K. L. (2012). 'Singapore among top 5 travel spots’. The Straits Times, 19 June.

Orbs (2007). In Chambers Dictionary of the Unexplained. Retrieved from http://www.credoreference.com.elibrary.jcu.au/entry/chambun/orbs

Parker I. (1992). Discourse Dynamics: Critical Analysis for Social and Individual Psychology. London: Routledge.

Rudez, H. N. (2006). Development of Hidden Assets in the Slovenian Tourism Industry.Economic and Business Review for Central and South - Eastern Europe, 8 (4), 325-335.

Raymond, J. (2006, Jul 01). Mysterious sightings: Young ghost hunters get a chance to search for the paranormal.McClatchy - Tribune Business News. Retrieved from http://search.proquest.com/docview/463522899?accountid=16285

Reisinger, Y. (2009). International Tourism: Cultures and Behavior. Burlington: Elsevier.

Selwyn, T. (Ed.)(1996). The Tourist Image: Myths and Myth Making in Tourism. Chichester U.K.: Wiley.

Seongseop K. S. \& McKercher, B. (2011).The Collective Effect of National Culture and Tourist Culture on Tourist Behavior. Journal of Travel \& Tourism Marketing.28 (2), 145-164.

Sharpely R. \& Stone P.R.(Eds.).(2012). Contemporary Tourist Experience: Concepts and Consequences. New York, NY: Routledge.

Sharkey, P. (2001).Hermeneutic Phenomenology. In R. Barnacle(Ed). Phenomenology, p. 16 -40. Melbourne: RMIT University Press. 
Starks, H. and Trinidad, S. B. 2007. Choose Your Method: A Comparison of Phenomenology, Discourse Analysis, and Grounded Theory. Qualitative Health Research, 17(10): 1372 - 1380.

Szarycz, G. S. (2009). Some issues in tourism research phenomenology: a commentary. Current Issues in Tourism, 12 (1), 47 - 58.

Tegelberg, M. (2012). Hidden sights Tourism, representation and Lonely Planet Cambodia. International Journal of Cultural Studies,13 (5), 5491-5509.

Tress, B.\&Tress, G. (2001).Capitalising on multiplicity: a transdisciplinary systems approach to landscape research.Landscape and Urban Planning,57, (3-4), 143-157.

Wang, Ning. (1999). Rethinking authenticity in tourism experience.Annals of Tourism Research, 26 (2), 349-370.

Watson, G. L. \& Kopachevsky, J. P. (1994).Interpretations of Tourism as Commodity. Annals of Tourism Research, 21 (3), 643-660. 